\title{
Rationing Bytes: \\ Managing Demand for Digital Forensic Examinations
}

\author{
Brian Rappert, Hannah Wheat, Dana Wilson-Kovacs
}

Forthcoming Policing \& Society

\begin{abstract}
With the growing sophistication and prevalence of digital devices such as mobile phones, computers, tablets, sat-navs, and domestic appliances, the extraction, analysis and interpretation of digital data has become increasingly central to intelligence gathering and criminal proceedings. However, the very extent of data available today challenges the ability of police agencies to turn seized devices into useful evidence. To date, most social science scholarship about forensics has concentrated on DNA profiling and its societal and ethical issues. In contrast, other forensic fields, including digital forensics, have had little analytical scrutiny. Based on unprecedented access to a forensic collaboration in England, this study addresses the question: In conditions of constrained resources, how do police agencies manage the insatiable demand for digital examinations? In doing so, we bring rationing classification schemes from healthcare studies into the field of criminology in order to characterise the techniques for reconciling demand with capacity. As detailed, formal attempts to ration demand are confounded by informal practices and procedures that can impact on the capacity of the workforce and the speed with which cases are processed. In addition, the rationing of digital devices has significant consequences for the definition and distribution of skills and expertise across criminal justice agencies.
\end{abstract}

Keywords: digital forensics; rationing; England; digital policing

Authors Note: Authors are listed in alphabetical order; authorship is distributed equally and the article should be cited as such. This work was supported by the Economic and Social Research Council under Grant ES/R00742X/1 (PI: Dana Wilson-Kovacs, Co-I: Brian Rappert and Sabina Leonelli). Our thanks to our participants for their insight, time and support, to our reviewers for their feedback and to Sabina Leonelli for her comments on previous drafts of this article. 


\section{Rationing Bytes:}

Managing Demand for Digital Forensic Examinations

\section{Introduction}

Increasing trends in crime involving computers (ONS 2018, Saunders 2017) and the ubiquity of digital devices - including computers, mobile phones, USB devices and other equipment - pose challenges for traditional agendas in policing (Home Office, 2016) and criminology (Smith et al. 2017). The ability to examine data from the devices of complainants, suspects and others has been recognised as of considerable importance (Casey et al. 2013). And yet, the vast and growing amount of data stored on individual devices confounds the efforts of some police forces to make it into useable information for investigations or criminal proceedings. The situation is compounded further by a general lack of understanding about how the examination of digital devices is conducted by some police agencies and the challenges faced in the selection of the devices with the most probative value.

The purpose of this article is to elaborate how the demand for the examination of digital devices is managed in four police forces in England against their limited resources and capabilities. By building on attempts to characterize how health care systems ration the provision of treatments (e.g., Klein and Maybin 2012, Williams et al. 2019), a classification scheme is used to map how some of the units responsible for conducting digital forensics (DF) as part of criminal investigations manage their activities. The article analyses the various rationing strategies at work in organising the delivery of digital forensics services and reflects on the implications of these arrangements on the abilities of forces to cope with the demand.

The paper is divided in seven sections. The next section provides an overview of recent policy discussions about DF within the criminal justice system and then focuses on the specific context of 
England and Wales. The third section outlines a framework for characterising the management of digital examination by considering approaches developed in health studies for conceptualising the rationing of healthcare. Section four elaborates and justifies the empirical research methods undertaken in the research presented in this article. The fifth section details the policies, procedures and practices across four Digital Forensics Units (DFUs), affiliated to the four English police forces studied. We examine how they prioritise and delimit which digital devices are given what kind of forensic scrutiny. The sixth section pulls out some cross-cutting themes and the final section concludes with some reflections on the limitations of the study.

\section{Digital Forensics - Policy Concerns \& National Context}

Digital technology has facilitated novel ways to commit old crimes and enabled new forms of criminal activity (Hitchcock et al. 2017). DF refers to "the process by which information is extracted from data storage media, rendered into a useable form, processed and interpreted for the purpose of obtaining intelligence of use in investigation, or evidence for use in criminal proceedings" (Forensic Science Regulator 2015, p. 3). Digital evidence can be found in multiple forms for most types of crime, through end-user devices (e.g., computers, smart phones, USBs, games consoles), network devices (e.g., routers, modems), public remote sources (e.g., websites, social media), private remote sources (e.g., IPS logs, cloud storage), and in transit communications (e.g., text messages, emails). This variety alone speaks to the complexity of forensic processes because of the different methods required to obtain data from each kind of device. The cost of evidence retrieval is difficult to predict and can rise suddenly due to requiring certain types of programmes that may be expensive or difficult to obtain.

In relation to the concerns of this paper, the application of DF in policing in England and Wales has had to contend with the same overall conditions of austerity faced by the police as a whole. The National Audit Office reported that, between 2010 and 2016, forces saw a 25\% real term reduction in national funding and 18\% overall. In addition, between 2010 and 2014 there was a related workforce 
reduction of over 36,000 (NAO 2015, p. 4-6). To offset the losses in funding, the Government argued that future funding can be drawn from savings made through forces becoming more streamlined, efficient and responsive to local demands, and able to harness new technologies (HCSTC 2017, p. 18). In forensics, spending on providing support services declined after $2009 / 2010$, in parallel with the estimated police spending (Home Office 2016, p. 26, see, as well, Wilson 2019). 2012 saw the Government's closure of the Forensic Science Service citing the organisation's financial losses and concerns over the quality of work (House of Lords Hansard 2018) and a shift to a commercial model for the provision of forensic service support.

The British Government's Forensic Science Strategy, published in 2016, promotes a vision for a clear governance system of forensic science support and a consistent national approach to the regulation of forensic services delivery in law enforcement. This vision has been criticised for devolving powers over service provision to each individual force (Home Office 2016). In the absence of a high-level governance framework, the 43 police forces in England and Wales utilise a variety of forensic support delivery models. What they all share is the requirement to manage their own forensic funding allocation from a reduced budget, reorganising procedures to best address demand, using in-house laboratories (where available), and/or private suppliers of forensic services. The amount of money spent on DF services in each force is presently unknown, which makes efficiencies difficult, if not impossible, to assess (HCSTC 2017, Tully 2018). What is clear, however, is that demand for DF outstrips capabilities, leading to backlogs (Home Office 2016). Recently, responding to the Government's call for harnessing new technologies to make savings through streamlined practices, the Transforming Forensics Programme and the Forensic Capability Network have been initiated. While these initiatives have been allocated a total of $£ 28.6$ million for $2020-2021$, it remains unclear how much of this funding will be specifically directed towards the application of digital forensics to crime examination. 
Existing literature on DF has been largely practitioner focused, with attention paid to: tool testing and verification methodologies (e.g. Garfinkel 2009, Casey 2011), specialist guidance (e.g. Marshall 2008), technical competencies (e.g. Lawton 2014), forensic standards (e.g. Tully 2018) and quality management procedures (e.g. Page et al. 2019). In the social sciences, the emphasis has been on: socio-legal and ethical aspects, such as the admissibility of digital evidence in court (e.g. Sommer 2010, Collie 2018), automated risk assessment tools (e.g. Christin 2017), offender identification (e.g. Horsman 2017) and cognitive bias (e.g. Sunde and Dror 2019). There is a growing body of expert literature addressing the pressures of coping with the demand for digital examinations, with some analyses describing processes of triaging to streamline workflow and allow digital forensics specialists to focus their expertise on complex analyses and most relevant exhibits (e.g., Casey et al. 2013, Hitchcock et al. 2016, Overill et al. 2013, Shaw and Browne 2012), and other studies exploring applications of DF in policing (e.g. James and Gladyshev 2013). For the latter, for instance, Van Baar et al. (2014) and van Beek et al. (2015) discuss the merits of the Digital Forensics as a Service (DFaaS) model, a centralised DF process model, provided by the Netherlands Forensics Institute to the Dutch law enforcement agencies, since December 2010. DFaaS has offered a national approach through standardised and centralised data extraction, delivering time efficiencies and cost reduction. However, when looking at England and Wales, there is a gap between specialist solutions and technical models proposed to deal with demand, on one hand, and information about whether and how they can be practically implemented in the UK context, on the other. Similarly, while triage has been long identified as a solution to coping with demand and encouraged nationally, to date, little is known about its in-situ implementation (Wilson-Kovacs 2019). It is at the junction between a vision for DF and current organisational - rather than technical - arrangements that this paper aims to make a contribution.

\section{Conceptual Framework}


Before setting out our empirical methods in section four, in this third section, we turn to our conceptual orientation for examining DF. While in theory, each investigation involving digital devices should be addressed with the same rigour, it is widely acknowledged that in practice this is not possible given the limited resources of police forces in the UK and elsewhere (Sommer 2004, Casey et al. 2009). The notion that the demands made on the police outstrip their ability to take action is familiar in criminological literature (e.g., Manning 1999[1978]). Classic studies of police officer discretion as well as the distinction between 'street' and 'management' cop cultures (Ianni and lanni 1983), share the starting presumption that officers are unable to respond to all the demands they experience. Both rank-and-file and senior managerial officers have been the focus of significant studies, but less research has taken place on backroom servicing civilian staff. One recent example is Lumsden and Black's (2018) examination of how financial austerity in England works to reaffirm traditional notions of 'real' police work in the context of a force control room. Below, we analyse how DF support services that are affiliated to police forces and largely consist of civilian police personnel, deal with escalating demand and limited budgets.

Similar to other European jurisdictions (Landström et al. 2019), police forces in England and Wales decide how to divide budgets and where to focus their limited resources. In this sense, the application of discretion extends beyond interactions with various publics, into what processes and steps need to be prioritised in order to achieve greater efficiency in crime examination. Managing restricted resources through delimiting service provision, however, is a pervasive condition for public sector organisations. For instance, demand for treatments routinely outstrips the ability of health care to respond. In any case, it would be impractical and unethical for health care systems to provide every service to patients that would have an expected benefit (Brock 2007). The British National Health Service (NHS) arrangements offer a valuable comparison for how service delivery decisions are delineated within the constraints of under-resourced budgets. Whereas the term 'priority setting' has come to designate decisions to allocate budgets to specific types of treatments and types of 
expenditure, 'rationing' refers to the decisions taken by doctors and other healthcare professionals who make treatment decisions within capped budgets (Klein 2010). In the NHS, the clinical 'bedside' rationing of treatments has been understood as pivotal to the management of scarcity in the past, as it remains today (Hall et al. 2018). Whereas priority setting tends to be explicit and subject to some form of organisational or public scrutiny, rationing is often undertaken within the discretionary powers of professionals. Most notably in the case of the NHS, general practitioners serve as gatekeepers for specialist services (Owen-Smith et al. 2015).

The now developed academic and policy debate about healthcare priority setting and rationing has centred on questions about their necessity, how they ought to be done, and how they are done in practice (Williams et al. 2019). Our focus in this article is with the last of these concerns, as it applies to DF. As elaborated in the previous section, against the growing demands for DF and the conditions of financial austerity, the need to reconcile demand with capabilities is a pervasive feature of DF in policing in England \& Wales today. We believe that normative efforts to determine how this reconciliation ought to be done, should be informed by an in-depth analysis of the lived experiences of police officers, staff and other stakeholders.

With regard to how rationing is done in practice, efforts have been made in health care studies to offer typologies. Klein (e.g., Klein et al. 1996, Klein and Maybin 2012) has proposed forms such as: delaying services (such as through the establishment of waiting lists), diluting the quality of services (for instance, by reducing staffing levels), deflecting individuals away from the NHS itself (for example, to social care), deterring patients from accessing services (for example, by not providing requisite information about possibilities), denying treatments (such as access to expensive drugs), selecting (for example, designating patient groups most likely to benefit from treatment) and terminating service provision. All these forms of rationing can be more or less explicit depending on how they are undertaken. In the remaining sections, we apply this typology to explain how four DFUs deal with the 
on-going demand for DF examinations. Our analysis of how rationing strategies are enforced in a policing context highlights the challenges they raise and how their outcomes impact on organisational routines and professional roles.

\section{Research Methods}

\section{Data Collection}

The qualitative data presented here derived from the first phase of a project on understanding the use of DF in policing. It was collected between 2018-2019 through ethnographic observations and semi-structured interviews, both methods acknowledged for providing richly textured, granular data on everyday interactions and exchanges that are otherwise difficult to document in complex settings, such as crime scene examinations and forensic contexts (Wilson-Kovacs 2018). Approximately 130 hours of ethnographic observations were undertaken at four in-house forensic support laboratories (DFUs) affiliated to four collaborating police forces in England. Observations captured a range of different technical processes, conducted by various professionals (e.g. technicians, data forensic investigators - including both mobile and computer examiners - and Team Leaders). Additionally, the everyday work environment (including interactions between police officers and the DFUs), regional meetings, training delivered by one of the DFUs and the Crown Prosecution Service (CPS), and visits by the United Kingdom Accreditation Service (UKAS) were observed. The second author (Wheat) documented each encounter, with all the three authors co-observing several of these events.

Additionally, 45 semi-structured interviews with DF practitioners, expert witnesses, and police officers (at various ranks of command) were conducted to provide a wider picture of how DF impacted upon the resolution of criminal investigations. Interviews typically lasted between 90-120 minutes and were audio recorded with the written informed consent of the participants. To supplement the qualitative data, the team also reviewed relevant national policy and internal guidance documents. The findings further draw, for background, on an additional 120 hours of ethnographic observations with the DFUs 
in question and 43 interviews undertaken by third author (Wilson-Kovacs) between 2017-2019, as part of a previous British Academy project. In order to protect the anonymity of the interviewees, DFUs and forces, identifiable details have been anonymised.

\section{Analysis}

Although at the start of the project, we (as authors) had not set out to examine rationing, demand management within DFUs was a pervasive theme in the ethnographic observations and semistructured interviews. We applied framework analysis (Gale et al. 2013, Smith and Firth 2011) once we identified coping with demand to be a central focus. In so doing, we were guided by classifications of rationing strategies used in health care services. A preliminary analytic framework was created and used to manage the organisation of the fieldnotes, by initially guiding the categorisation of the data and later by facilitating comparisons of how rationing was done.

Key tenets of framework analysis (Srivastava and Thomson 2009) were used to inform the steps we took, first by familiarising ourselves with the 2018-2019 data, before mapping it onto existing healthcare rationing strategies. The mapping was achieved by examining fieldnotes and interview transcripts for entries that provided examples of rationing strategies. Instances of rationing that did not easily map onto the existing framework were kept for later analysis and eventual classification consensus. Subsequently, each of the authors coded the qualitative data under each category, so that unique rationing strategies could be identified and serve as category themes. A review of the initial mapping and thematic work sought to establish: 1) that each mapped entry was an example of rationing, 2) whether the identified DF examples matched the original healthcare rationing label and 3) whether adjustments to the initial thematic framework needed to be made. Consequently, the authors agreed that the existing rationing classifications had provided a suitable analytic starting basis. However, as in the case of other rationing studies (e.g., Owen-Smith et al. 2015), the overall 
framework needed adaptation to the context of this study. Three overarching rationing categories, discussed below, emerged as a result:

1. Sorting - rationing forms related to how devices are categorised and assessed,

2. Transferring - rationing forms related to whether examinations are undertaken, by whom and under what terms, and

3. Diminishing - rationing forms related to the speed or extensiveness of examinations.

\section{Findings}

\section{Background}

Prior to providing an account of the various rationing strategies observed in the DFUs, in this section we present an overview of the working environment studied to give an insight into the extent to which rationing strategies are used and how they may impact upon specific practices or concerns. This contextual information may also help the reader understand why some arrangements have heighted the pressures experienced by the DFU teams, rather than alleviated them (see also Discussion section below).

The four DFUs studied were tasked with a number of duties, such as: 1) gatekeeping and prioritising the digital device submissions made by police officers, 2) maintaining the continuity of digital devices once they are in their possession, 3) assigning examiners to cases and monitoring case progression, 4) establishing suitable examination strategies with the officers conducting the investigation, 5) extracting and creating a copy of digital data from submitted devices and then 6) examining, analysing and reporting on the evidence found. All these steps were recorded and monitored through a case management system shared across the four teams. Around $3 / 4$ of the work involved child sexual abuse cases, consisting of possession, distribution and occasionally production of indecent images of children. The remaining workload involved sexual offences (e.g., grooming, voyeurism, assault or rape), and serious and major crime offences (e.g., murder and drug charges). All the units had 
technicians, mobile devices examiners and computer investigators, who worked a varied pattern of hours. One unit had additional administrative support for receiving items. High staff turnover, a limited candidate selection pool and long-term staff absence due to sickness, were experienced by all the units.

DF practitioners felt a great sense of personal reward from their work, which involved routinely dealing with high risk cases that were in the wider public's interest to resolve. However, the nature of their work brought considerable pressure, as the evidence they produced was key in most cases and failure to produce it could lead to new serious offences against the highly vulnerable. Increased pressure was also experienced when police officers expected the DF components of their investigation to be prioritised over other cases. In these situations, DF practitioners noted the tension between providing quality examinations and making good progress with their queue of cases, which could all benefit from immediate attention. They also voiced concerns about depleted levels of resources (such as staff, software and training) and the constraints imposed on their working practices by the implementation of accreditation standards.

\section{Rationing strategies}

Rationing by sorting

Similar to Hughes and Griffiths' research on the micro-rationing of health care (1997), the most prominent technique of dealing with demand in the four forces is selection. However, while in the healthcare sector selection is managed implicitly (Owen-Smith et al. 2015), in DF, the drive for selection has been framed nationally through triage. Triage focuses the forensic examination on the samples that are more likely to bring valuable information to the investigation, by deciding whether cases are to be moved to the next stages of examination to remove 'time-wastage' (Julian and Kelty 2015). Typically, this takes place before seized items enter the DFUs and the results of the process partly determine whether these devices are formally submitted into DFUs for examination. An internal 
survey at one of the DFUs, taken prior to the introduction of triage in 2007, showed that on average $70 \%$ of seized devices did not hold any evidence of value to an investigation. Triage is achieved with automated tools and specialist software. Generic, pre-loaded profiles, adapted by each DFU to suit different types of searches, are used to check for indication that potential evidence is available on the seized devices, and therefore suitable for detailed analysis. Unlike some forces that deploy triage to decide which mobile and computer exhibits should be analysed first, the practice in the forces studied here, has been to actively eliminate devices from examination. While this approach carries with it the risk that evidence is missed if the device containing proof is excluded from the examination, this risk is mitigated by the fact that evidence may be found on other devices owned by the suspect.

Given the growing demand for the examination of mobile phones, whose seized numbers far exceed those of other electronic devices, operational attempts to manage officers' requests for their analysis have also been made through kiosk arrangements designed to triage and reduce the number of mobile phones intended for in-depth DF analysis. Kiosk arrangements provide frontline officers with a basic level of data extraction that in some cases may be sufficient for the investigation. In the forces studied, the management of mobile phone demand is overseen by the DFUs but undertaken by crime scene examiners.

Once mobile phones, computers and other devices are selected as part of a case, their examination is prioritized through a formal risk-assessment matrix, developed from the 2012 National Police Improvement Agency's (NPIA's) High-Tech Crime Unit Case Prioritisation Matrix. The matrix poses various questions to officers related to the relevance of the digital evidence to the case, including the type of offence under investigation, the suspect's details and several risk factors (including to the public and the force). Affirmative responses to the questions are given a score (one that is not generally known to officers, see below) and the total score for a case determines its categorisation as High, Medium, or Low Priority and its rank in the workload queue. If a case receives a score under a 
certain point threshold, it can be denied authorisation for examination. In practice, however, rather than simply being outright barred, the officers in charge will talk through their submission with DFU Team Leaders, as part of standard communications about case scores. Such discussions can involve determining whether a case should merit examination, or what further developments might take it above the points threshold.

As a means of prioritisation, the matrix embodies a set of values about the relative significance of investigating certain offences, and, thereby, whether and how quickly cases should be progressed. For instance, homicide, crimes pertaining to national security, life altering violence, serious sexual assault, and kidnapping are given significant points. In contrast, crimes involving other violence and drug dealing offences receive comparatively few points. As with other risk-assessment tools used in police, the matrix aims to establish a shared agreement across forces about the relative importance of certain offences, instead of leaving it to individual constabularies to derive their own priorities.

While the applications of many general matrix criteria to specific cases were regarded as relatively straightforward by interviewees, sometimes this was not the case. This included, for instance, varied interpretations associated with the qualifiers related to the criterion "known and immediate risk of serious harm to life' as well as diverse orientations taken to determine whether a criminal investigation posed a 'serious harm to reputation or family life'. Investigating police officers were required to fill in the risk assessment matrix on their own, with the potential for clarifying questions from DFUs. However, the lack of clarity regarding matrix criteria was partly responsible for a transference of responsibility and workload onto the DFUs, as DFU Team Leaders reported spending considerable time gatekeeping submissions through querying and revising initial assessments completions by officers. Furthermore, at least one Team Leader double-checked internally outsourced devices in relation to other units' interpretation of specific criteria. 
The examination of devices can be terminated for varied reasons other than to do with their relevance for a case. First, examinations can be discontinued if officers fail to supply intelligence necessary for the examinations to proceed. Secondly, in some situations the extended waiting (see delay below) can mean examinations are no longer deemed as necessary for investigations by officers. Thirdly, once an evidence threshold is reached, the examination of devices can be stopped in relation to offences pertaining to the possession of indecent images of children.

\section{Rationing by transferring}

In terms of deflection, one management strategy observed is to outsource exhibits to commercial forensic services companies (POST 2016). Not all the DFUs studied used this facility - those that did, outsourced at different points throughout the year, such as when the unit was understaffed (for instance, during summer periods). An often-quoted rationale for outsourcing was getting through the bulk of the less complex cases. However, the quality of examinations provided for outsourced exhibits was sometimes rated as lower than that provided by the in-house teams, and occasionally, exhibits were re-examined upon return.

In addition to external outsourcing, each of the DFUs were also able to internally source as part of the arrangement held with the other three DFUs, by transferring cases through their case management system. Two different events prompted this: first, when practitioners at the receiving unit were better equipped to undertake a specific type of digital extraction due to the specialisation of staff in a distinct DF area (such as chip-off expertise for mobile phones). Secondly, bulk case transfers happened when one of the DFUs had a disproportionately sized queue of cases awaiting examination, compared to some of the other DFUs (this was observed once and was attributed to the pressures raised by an impending accreditation assessment visit). 
Deterring as a rationing strategy was also manifest in the guidance documents and bulletins produced to: enhance frontline officers' understanding about what types of personal devices can hold digital evidence, how and what officers should seize from a crime scene, how exhibits should be submitted to the DFU (including the number of devices and required information) and why a DFU may refuse submissions. Such guidance seeks, in part, to deter officers from submitting too many exhibits to the DFUs and emphasises that officers must select and prioritize what needs to be examined, based on the intelligence they already possess.

A second instance of deterrence was observed when, following a decision by one of the DFUs and the CPS team serving that region, training sessions were offered to CPS personnel and police units involved routinely in submissions to the DFUs (e.g., Major Crime Investigation, Public Protection and Serious and Organised Crime teams). The sessions aimed to familiarise participants with the work undertaken by DF practitioners and the challenges they experience. Presenters from both the CPS and DFU sought to illustrate, through quantified and qualitative accounts, how extensive digital evidence can negatively impact upon the speed and efficiency of case progression. The attendees were informed about the pressures DFUs face due to limited resources, ISO accreditation and bureaucratic procedures. Repeated reminders were made regarding the CPS' remit to follow reasonable lines of enquiry (as opposed to all). While no definitive guidance was offered on what and how many digital devices the CPS should be asking DFUs to examine, there was an overt, verbal appeal for the attendees to break away from the current culture of seizing and examining all devices.

The extent of delegation is the final sub-category of rationing by transferring and refers to how decisions about examining the extracted data are made. DFU practitioners used a number of strategies to narrow down the amount of data they needed to focus on. Keyword searches, for example, enable them to identify potential evidence within such data, sparing them from the onerous task of reviewing all the data on a device (Billingsley 2016). These searches were routinely used to assist the 
examinations of devices connected to suspected child abuse cases, with a pre-set list of keywords commonly associated with this type of offence, added to search criteria at the start of an investigation. Another instance was adding distinct terms (e.g., a suspect's name and/or telephone number), unique to each case, to searches in order to speed up the identification of evidence. A third example, specific to computer examinations, is the manual or tool assisted identification of unallocated disk space on a device (referred to as 'file carving'), to ascertain whether specific files have been hidden (see Sammons, 2015 for more technical details).

\section{Rationing by diminishing}

One of the ways in which the extent of demand for DF is matched to existing examination capacity is by delay. While the examination of cases ranked as High, Medium or Low through the Prioritisation Matrix are meant to start within 1, 2 and 3 months respectively, in practice, devices can remain in a queue for longer. In one of the DFUs studied, at the time of fieldwork, computers ranked as 'High' had been in the queue for more than 8 months and mobile devices ranked as 'High' for more than 6 months. As previously noted, these delays were attributed to the demands of preparing the DFU for ISO accreditation, preparations noted to contribute significantly to the length of the queues. Finally, one of the ways DFUs sought to match supply with demand, was by diluting the extent of the services provided, by limiting the number of items accepted for examination. In practice, however, the number of items submitted varied according to the perceived severity of the offence.

\section{Discussion}

This section extends the insights provided above on how extensive demand for DF gets reconciled with the limited capacity for examinations, by considering how rationing is negotiated in practice and on the implications of rationing efforts.

\section{Rationing Negotiations}


Building on debates on how the allocation of limited resources is dealt with in health care, this article has sought to detail descriptively how capacity and demand are reconciled for DF in four English forces. Our analysis shows that rationing occurs as part of both administrative processes, designed to streamline the processing of exhibits, and through in-built technical features of DF tools. Echoing Williams et al. (2019) interviewees' reactions to health service rationing, our participants agreed, in principle, with the necessity of some form of rationing DF services, but feared that the measures taken did not fully address the pervasive shortage of resources.

As noted in relation to rationing in the health services (e.g., Chabrol et al. 2017) and priority setting in the police (e.g., Landström et al. 2019), explicit, formal and central efforts to direct resources can often be accompanied by implicit, discretionary local decision making. This is reflected in our findings, where the development of national and cross-force initiatives to establish shared policies has been accompanied by situated practices that interpret such policies against local demands. Moreover, similar to findings in public health service literature (Light and Hughes 2001), multiple rationalities underpin the decisions accompanying the forensic examination of digital devices in local contexts.

The dynamics between the explicit and the implicit are evident in the significant deliberation and interpretation surrounding the nature and extent of digital examinations. While members of the DFUs and police recognised the need for strategies that could help the DFUs manage and prioritise the large amount of digital data received for examination, occasional reluctance to adhere to formal policies was noted. For example, on occasions, police officers would challenge where the NPIA Case Prioritisation Matrix placed their cases in the queue. This reluctance led to officers contacting the DFU to question the ranking of their case, arguing that the case warranted a higher prioritisation score and offering additional information on the specific needs and nature of the case. Equally, prior to commencing in-depth examination, DFU gatekeepers would often contact submitting officers to gain 
more clarity, and if necessary, further information about the case, to ensure that its severity and/or the intel received had been adequately captured in the score given. ${ }^{1}$

Consequently, the extent to which denial strategies could be imposed was severely limited as submissions were regularly reassessed. Thus, interpretation on behalf of DF examiners and gatekeepers, and officers' reluctance to accept the application of rationing strategies to their own cases, impeded rationing efforts by adding lengthy deliberations to submissions. DFU Team Leaders estimated that it took up to half a day, every day, to manage case submissions to their unit as well as triage and kiosk activities. The cost and impact of gatekeeping all these aspects of priority setting remain unknown, as the time they take is neither captured in DFU workloads, nor reviewed in performance data. What is clear however, is that such burdens significantly reduce the Team Leaders' capacity to steer how organisational reforms could be best implemented to improve their units' ability to meet demand. The efforts to formally delimit cases have led to further administrative work that remains invisible through the very systems designed to manage staff time and monitor performance. Thus, different techniques for rationing can conflict with, rather than enhance, one another - in this case, selection processes reduced the abilities of DFUs to enact denial techniques. Denial becomes difficult to realise against: 1) inadequate intel within submissions forms, due to a lack of understanding or time; 2) the opportunity to modify paperwork to ensure successful submission and 3) the scope for varied interpretations between and within DFUs and police officers regarding examination criteria.

Related issues associated with the frustration raised by limiting demand for DF service pertain to the kind of adjustments enabled through a formalized system. Given that the ranking in the risk assessment matrix was not widely communicated to officers, DF practitioners feared that officers with a greater knowledge of the submission process were in the position to know how to achieve a higher classification of their case and thereby place their devices higher in the queue. For instance, as a way of raising the ranking of a case, officers could indicate digital evidence was 'essential' (as opposed to 
'significant') to a criminal investigation. In an effort to counteract this possibility, Team Leaders spent less time on other tasks in the unit.

The practice of challenging the DFU admission policies was noted in some of the officers' depictions of their submissions to the electronic case management system. Officers stated that when faced with an initial rejection of their submission, they re-applied, modifying entries until these were formally accepted. These officers' perseverance with the process was reportedly driven by pressures from their senior lead investigators to ensure that all the case-related seized devices had been accepted for DF examination and each possible line of inquiry was pursued. An additional justification for the officers' decision to modify initially rejected submissions until they were accepted, was the lack of clarity regarding what information was needed for submissions. Such practices suggest the limits of formal policies designed to curtail the demand for DF examinations in the absence of significant organisational and cultural changes.

\section{Rationing Implications}

One important implication of the rationing processes observed above is how they impact upon the skills of the professional groups involved: digital forensics examiners, police officers and crime scene investigators. In relation to the first, for instance, the usefulness of triage, lies not only in the speed with which seized items can be eliminated from an investigation, but also in the fact that it does not require the user to have large amounts of expertise or training. Triage is intended to allow digital forensics examiners to focus on the items with the most probative value and thus use their expertise in the most effective way. While this is largely the case, the amount of time dedicated to the deliberations surrounding the prioritisation of cases and the ongoing clarifications between the examiners and officers over particular aspects of a case at any one time, impacts on the time allocated to DF analysis. At a collective level, other pressures, such as the demands of ISO accreditation and the validation and verification of methods, also contribute to restricting the time left for in-depth 
examination and the DF practitioners' sense of their changing roles. The use of keyword searches outside triage adds an additional dimension to the ways in which some of those interviewed see their role changing, both in terms of the restricted time allocated to each case, and the dilution of skills required to process evidence through 'push-button' forensics.

In terms of the second professional group involved, i.e. the officers that oversee the management of triage, their skill set is impacted through the additional training required to become effective gatekeepers. Often, efficiencies generated by the delegation of officers to triage activities are offset by training high numbers of staff each year to cater for officers moving roles within the force, or through officers not using their triage skills often enough (Wilson-Kovacs 2019). Officers need to remain familiar with the technology and become well-versed with triage procedures, at both technical and administrative levels, in order to avoid mistakes that can: invalidate procedures, interfere with the authentication of findings or the processing of evidence and may lead to the exclusion of items for examination (Cantrell et al. 2012).

While the involvement of the third professional group, crime scene examiners, in the processing of kiosk submissions can be seen as enhancing their skill-set and their relevance and value, the ability to undertake the basic analysis of mobile phones adds to a growing range of duties, which is seen by some of these specialists as a challenge to their original expert role that subtracts from their core duties, rather than adding to their portfolio (Wilson-Kovacs 2014).

Moreover, our findings highlight issues with the lack of knowledge amongst frontline officers that impacts upon seizure and submission processes. While guidelines and systems are in place to provide officers with advice on how to navigate these processes, they appear insufficient. This echoes earlier observations regarding the lack of skills pertaining to investigation and frontline officers in relation to DF (House of Lords Hansard 2018), and the gap in the infrastructure required to provide non-specialist 
officers with the basic digital knowledge required. It also suggests that DF cannot be thought of and developed simply in terms of the specialist units and that a more pervasive understanding of digital evidence is needed at all operational levels. Finally, the adoption of rationing strategies often results in an unacknowledged and increased workload, and uncertainty in the perceived change of the roles of those involved. In turn, the lack of investment in continuous and adequate non-specialist and practitioner training, heightens the risk of miscarriages of justice and reputational loss, and threatens to damage the legitimacy of the police.

\section{Conclusion}

Given the increasing centrality accorded to digital evidence in criminal investigations and the vast amounts of data available for examination, this article discussed how limited forensics capacities are managed in four English DFUs. To our knowledge, it represents one of the first attempts to map in detail how UK policing organisations, responsible for undertaking DF examinations, practically manage their day-to-day work despite restricted capacity. The research presented was based on documentary, interview and observation methods that enabled the authors to compare and contrast Government recommendations and formal arrangements to the day-to-day undertaking of DF examinations. The marshalling of data across different research projects also enabled longitudinal trends to be identified. However, the analysis is limited in its ability to provide a generalised understanding of DF in England and Wales in a number of respects: first, it only covered four DFUs belonging to four of the forty-three existing police forces. Secondly, the DFUs examined worked mostly on cases relating to indecent images of children and the policies and practices referred to in the article have reflected this orientation. Thirdly, while the DFUs were the primary organisations conducting DF examinations in the four forces studied, such examinations were also conducted by private companies that the laboratories outsourced some of their work to. 
Our analysis has provided a framework for characterising and comparing how forces manage demands for DF in a context where demand exceeds capabilities. It has also illustrated how a complex web of value-laden force and national policies along with the situated contingencies of local practices have collectively impacted DFU decisions on whether and how to examine case exhibits. Within this decision-making process, formal determinations were made of what kind of cases merited what kind of attention and who was in a position to make such determinations. Discretionary practices accompanied these assessments. Given the complexity of decisions required and their implications for victims, suspects and the criminal justice system, further attention needs to be paid to the ways in which formal policies are reflected in informal practices. The manner in which rationing activities generate extensive checks and discussions illustrates how additional demand can be created as a direct consequence of actions intended to alleviate workloads and speed up processes. Our description of currently implemented rationing practices has shown how in the face of a historic lack of DF support and preparedness to deal with increasing demand, service has still been provided. While those interviewed expressed promise in the ability of sorting, transferring and diminishing techniques to help manage caseloads, a common refrain was that the shortage of available resources hindered the provision of a prompt service to the needs of the police and the courts. To this end, the work planned as part of the Transforming Forensics Programme could provide much needed guidance. More generally, discussions on digital policing, its provision and uptake, need to consider how increasing demand is effectively addressed by the rationing strategies adopted, as well as their wider implications. 


\section{References}

Association of Chief Police Officers (ACPO) 2012. Good practice guide for digital evidence. Version 5, October.

Billingsley, J., 2016. Beyond keywords: Is keyword search becoming obsolete https://articles.forensicfocus.com/2016/03/11/beyond-keywords-is-keyword-search-becomingobsolete-in-the-new-age-of-forensic-digital-investigation/ [Accessed on 14 June 2019].

Brock, D.W. 2007. Health care resource prioritization and rationing. Social research, 74(1), 125-148.

Cantrell, G., Dampier, D., Dandass, Y.S., Niu, N. and Bogen, C., 2012. Research toward a partiallyautomated, and crime specific digital triage process model. Computer and information science, 5(2), 29-39.

Casey, E., Ferraro, M. and Nguyen, L., 2009. Investigation delayed is justice denied: proposals for expediting forensic examinations of digital evidence. Journal of forensic sciences, 54(6), 1353-1364.

Casey, E., Katz, G. and Lewthwaite, J., 2013. Honing digital forensic processes. Digital Investigation, 10(2), 138-147.

Chabrol, F., David, P.M. and Krikorian, G., 2017. Rationing hepatitis C treatment in the context of austerity policies in France and Cameroon: A transnational perspective on the pharmaceuticalization of healthcare systems. Social science \& medicine, 187, 243-250.

Chapman, R., 2019. Computer Forensic Analysis. Retrieved from: https://www.oas.org/juridico/spanish/cyber/cyb35 analysis2.pdf [Accessed on 14 June 2019]. 
Christin, A., 2017. Algorithms in practice: Comparing web journalism and criminal justice. Big data \& society, 4(2), https://doi.org/10.1177/2053951717718855 [Accessed on 14 June 2019].

Collie, J., 2018. Digital forensic evidence. Flaws in the criminal justice system. Forensic science international, 289, 154-155.

Forensic Science Regulator. 2014. Codes of practice and conduct. Appendix: Digital forensic services FSR-C-107 Issue 1.

Forensic Science Regulator. 2015. Newsletter October 26(3).

Forensic Science Regulator. 2016. Codes of practice and conduct. Appendix: Digital forensics - cell analysis. FSR-C-135 Issue 1.

Gale, N.K., Heath, G., Cameron, E., Rashid, S and Redwoodm, S., 2013. Using the framework method for the analysis of qualitative data in multi-disciplinary health research. BMC medical research methodology, 13, 117.

Garfinkel, S.L., 2013. Digital media triage with bulk data analysis and bulk extractor. Computers \& security, 32, 56-72.

Hall, W., Williams, I., Smith, N., Gold, M., Coast, J., Kapiriri, L., Danis, M., Mitton, C., 2018. Past, present and future challenges in health care priority setting: findings from an international expert survey. Journal of Health organisational management, 32(3), 444-462. 
HCSTC (House of Commons Science and Technology Committee). 2017. Forensic science strategy Fourth Report of Session 2016-17. London: HMSO.

https://publications.parliament.uk/pa/cm201617/cmselect/cmsctech/501/501.pdf [Accessed: $19 / 05 / 2018]$.

Hitchcock, A., Holmes, R., and Sundorph, E., 2017. Bobbies on the net: A police workforce for the digital age. Reform. https://reform.uk/research/bobbies-net-police-workforce-digital-age [Accessed: 20/10/2018].

Hitchcock, B., Le-Khac, N.A. and Scanlon, M., 2016. Tiered forensic methodology model for Digital Field Triage by non-digital evidence specialists. Digital investigation, 16, March Supplement, S75-S85.

Home Office. 2016. Forensic science strategy. London: HMSO.

Home Office. 2018. The Child Abuse Image Database (CAID). Retrieved from:

https://assets.publishing.service.gov.uk/government/uploads/system/uploads/attachment data/file 1759328/CAID Brochure May 2018 for gov uk.pdf. [Accessed on 14/06/2019].

Horsman, G., 2017. Can we continue to effectively police digital crime? Science \& justice, 57(6), 448454.

House of Lords Hansard 2018. 'Digital forensic services' 12/03, Vol.789, https://hansard.parliament.uk/Lords/2018-03-12/debates/DAB3481A-984E-4123-9EBC213C458971EC/DigitalForenicServices [Accessed 19/05/2018].

Hughes, D. and Griffiths, L., 1997. "Ruling in" and "ruling out": Two approaches to the microrationing of health care. Social science \& medicine, 44(5), 589-599. 
James, J.I. and Gladyshev, P., 2013. A survey of digital forensic investigator decision processes and measurement of decisions based on enhanced preview. Digital Investigation, 10(2), 148-157.

Julian, R. and Kelty, S.F., 2015. Forensic science as "risky business": identifying key risk factors in the forensic process from crime scene to court. Journal of criminological research, policy and practice, $1(4), 195-206$

Klein, R., 2010. Rationing in the fiscal ice age. Health economic policy law, 5(4), 389-396.

Klein, R., Day, P., Redmayne, S., 1996. Managing scarcity: Priority setting and rationing in the National Health Service. Milton Keyes: Open University Press.

Klein, R. and Maybin, J., 2012. Thinking about rationing. London: King's Fund.

Landström, L., Eklund, N. \& Naarttijärvi, M., 2019. Legal limits to prioritisation in policing challenging the impact of centralisation, Policing \& society, DOI: 10.1080/10439463.2019.1634717

Light, D.W., \& Hughes, D. (2001). Introduction: a sociological perspective on rationing: power, rhetoric and situated practices. Sociology of health \& illness, 23(5), 551-569.

Lumsden, K. and Black, A., 2018. Austerity policing, emotional labour and the boundaries of police work: an ethnography of a police force control room in England. The British journal of criminology, $58(3), 606-623$ 
Marshall, A., Higham, S., and Dyhouse, T., 2013. Digital forensics capability review. Special Interest Group Forensic Science, June.

https://www.researchgate.net/publication/269332581 Digital Forensics Capability Review [Accessed on 31/05/2018]

Moreira, T., 2011. Health care rationing in an age of uncertainty: a conceptual model. Social science \& medicine, 72(8), 1333-1341.

National Audit Office 2015. Financial sustainability of police forces in England and Wales. HC 78 London: NAO. Retrieved from: https://www.nao.org.uk/wp-content/uploads/2015/06/Financialsustainability-of-police-forces.pdf. [Accessed on 20 June 2019].

Office for National Statistics 2018. Overview of fraud and computer misuse statistics for England and Wales. Available at

https://www.ons.gov.uk/peoplepopulationandcommunity/crimeandjustice/articles/overviewoffraud andcomputermisusestatisticsforenglandandwales/2018-01-25. [Accessed on 10 May 2020].

Overill, R.E., Silomon, J.A. and Roscoe, K.A., 2013. Triage template pipelines in digital forensic investigations. Digital Investigation, 10(2), 168-174.

Owen-Smith, A., Donovan, J. and Coast, J., 2015. How clinical rationing works in practice: a case study of morbid obesity surgery. Social science \& medicine, 147, 288-295.

Page, H., Horsman, G., Sarna, A. and Foster, J., 2019. A review of quality procedures in the UK forensic sciences: What can the field of digital forensics learn? Science \& justice, 59(1), 83-92. 
Parliamentary Office of Science and Technology. 2016. Digital forensics and crime.

Retrieved from: https://researchbriefings.parliament.uk/ResearchBriefing/Summary/POST-PN-0520.

[Accessed on14 June 2019].

Privacy International. 2018. Digital stop and search: how the UK police can secretly download everything from your mobile phone. March 2018. Available at

https://privacyinternational.org/report/1699/digital-stop-and-search-how-uk-police-can-secretlydownload-everything-your-mobile . [Accessed on 10 June 2019].

Sammons, J., (2015). 'Unallocated Space' in The basics of digital forensics. (Second Edition) Amsterdam: Syngress, 66-85.

Saunders, J., 2017. Tackling cybercrime-the UK response. Journal of Cyber Policy, 2(1), pp.4-15.

Schwartz, W.B. and Aaron, H.J., 1984. Rationing hospital care: lessons from Britain. New England journal of medicine, 310(1), 52-56.

Shaw, A. and Browne, A., 2013. A practical and robust approach to coping with large volumes of data submitted for digital forensic examination. Digital Investigation, 10(2), 116-128.

Smith, G.J., Bennett Moses, L. and Chan, J., 2017. The challenges of doing criminology in the big data era: towards a digital and data-driven approach. The British journal of criminology, 57(2), 259-274.

Smith, J., Firth, J., 2011. Qualitative data analysis: application of the framework approach. Nurse researcher, 18(2), 52-62.

Sommer, P., 2004. Emerging problems in digital evidence. Criminal justice matters, 58(1): 24-25. 
Sommer, P., 2010. Forensic science standards in fast-changing environments. Science and justice, 50(1), 12-17.

Srivastava, A. \& Thomson, S.B., 2009. Framework analysis: A qualitative methodology for applied research note policy research. JOAAG, 4(2), 72-79.

Sunde, N. and Dror, I.E., 2019. Cognitive and human factors in digital forensics: Problems, challenges, and the way forward. Digital investigation, 29, 101-108.

Tully, G., 2018. Annual Report November 2016 - November 2017. Birmingham: Forensic Science Regulator. Accessed on 15 September 2018 https://assets.publishing.service.gov.uk/government/uploads/system/uploads/attachment_data/file /674761/FSRAnnual_Report_2017_v1_01.pdf

Van Baar, R.B., Van Beek, H.M.A. and Van Eijk, E.J., 2014. Digital Forensics as a Service: A game changer. Digital Investigation, 11, Supplement 1, 54-S62.

Van Beek, H.M.A., van Eijk, E.J., van Baar, R.B., Ugen, M., Bodde, J.N.C. and Siemelink, A.J., 2015. Digital forensics as a service: Game on. Digital Investigation, 15, 20-38.

Williams, I., Allen, K., Plahe, G., 2019. Reports of rationing from the neglected realm of capital investment: Responses to resource constraint in the English National Health Service. Social science \& medicine, 225, 1-8.

Wilson, T., 2019. The impact of Brexit on the future of UK forensic science and technology. Forensic Science International 302 https://doi.org/10.1016/j.forsciint.2019.06.028. 
Wilson-Kovacs, D. 2019. Effective Resource Management in Digital Forensics: an Exploratory Analysis of Triage Practices in Four English Constabularies. Policing: An International Journal of Police Strategies and Management, 43(1), 77-90.

Wilson-Kovacs, D. 2018. An Ethnographic Approach to Researching the Introduction of New Forensic DNA Technologies in Policing in the UK. London: Sage Research Methods Cases. DOI:

https://dx.doi.org/10.4135/9781526445315.

Wilson-Kovacs, D. 2014. Clearly Necessary', 'Wonderful' and 'Engrossing'? Mass Observation Correspondents Discuss Forensic Technologies. Sociological Research Online, 19(3).

\section{Notes}

\footnotetext{
${ }^{1}$ Despite the time spent by DF Team Leaders to effectively gatekeep submissions, DF practitioners often found the available intelligence insufficient for their examinations. Problems of interpretation occurred during the selection of devices phase and continued to shape the subsequent steps taken by DFU towards examination. For example, information requested from police officers for selection purposes will later be utilised by DF investigators to determine search strategies for the identification of relevant digital evidence for further examination. Common complaints by DFU practitioners were that officers ask for evidence relating to a key figure in the case but omit any identifiable details about that person (such as a name or a phone number that could be used in keyword searches) or insist on inconsequential terms for such searches. While DF practitioners were able to exercise some flexibility in what they searched for, having more details about persons of interest at the beginning of their investigation could speed the analysis and benefit service provider-client relations.
} 